\title{
INDÍGENAS E INDIOS EN EL CARIBE: PRESENCIA, LEGADO Y ESTUDIO
}

\author{
Juan Manuel Reyes Cardero
}

\section{Reseña del libro}

Indigenas e Indios en el Caribe. Presencia, legado y estudio, volumen I de la serie Los Indígenas más allá de Colón es una obra compilada y editada por los doctores Jorge Ulloa Hung y Roberto Valcárcel Rojas, que representa un esfuerzo serio por dar a conocer pruebas convincentes que demuestran la pervivencia del llamado indio en la sociedad colonial de las Antillas Mayores hasta avanzado el siglo XIX.

Además del análisis de algunas de las aristas teóricas y metodológicas con que se ha tratado el tema del legado indígena, y enfatizar en reflexiones críticas que priorizan un redescubrimiento de estos individuos y sus comunidades, tal y como anuncian estos investigadores en su prefacio, el libro se alinea con el desvelo por el rescate del indio emprendido por muchos estudiosos de esta área geográfica durante el siglo XIX y el siglo XX.

Adecuadamente interconectados con las nuevas ideas sobre estos temas, los ensayos aquí presentados compendian, con un sentido interpretativo, una notoria cantidad de trabajos aislados que forman parte de la intermitente dialéctica investigativa que ha reevaluado e insistido en la pervivencia del indio en la sociedad colonial antillana. Esta es la mejor contribución de los siete trabajos expuestos en las dos primeras secciones del texto. Como colofón, en la tercera sección, a manera de homenaje se presentan sendos artículos de los valiosos arqueólogos de Cuba y República Dominicana, María Nelsa Trincado y el Marcio Veloz Maggiolo.

El prólogo de la doctora Olga Portuondo es muy sugerente, no solo porque justiprecia el buen valor de los escritos del libro, al decir que cambia la perspectiva desde donde se ha analizado el pasado indígena en cada una de estas islas del Caribe, sino también porque sin poderse despojar de su juicio de infatigable investigadora nos ofrece lecciones de cómo el indio se fue insertando en la sociedad colonial cubana, a través del sincretismo religioso, del intercambio cultural, y de su aporte a la obra colonizadora. Por ello, vuelve sobre sus pasos al abordar la presencia del indio en la conformación del mito de la Virgen de la Caridad del Cobre, de la religiosidad popular, y de cómo aprendieron la montería. Para fundamentar esto, se apoya en documentos como la carta de relación de Diego Velázquez, los autos para el conocimiento del culto de la Virgen y los relatos sobre Onofre de Fonseca y Mathías de Oliveira. Culmina sus consideraciones, 
haciendo referencia a sucesos del año 1783, en los que según una memorable descripción, los esclavos de las minas del Cobre en Santiago de Cuba se hicieron eco y defendieron ante el monarca su condición de naturales, a través de su autoreconocimiento como descendientes de la mezcla de indios, negros y blancos.

El primer trabajo del libro, "Indios después de Colón”, del Dr. Roberto Valcárcel Rojas, aunque parecía en su introducción severamente crítico, al afirmar que "domina la historia cubana la idea de que el indio no encuentra modos de inserción en el panorama construido", y además resulta sumamente categórico al decir que "los indios y sus descendientes tomaron su propio camino hasta el presente", constituye un estudio de sumo interés, de los mejores de este volumen, y un resumen enjundioso de los principales resultados de investigación arqueológica y etnológica (documental) que permiten avalar buena parte de la impronta indígena en la sociedad colonial cubana.

Además de propiciar la comprensión de la categoría indio, Valcárcel realiza una retrospectiva que se vincula al entorno histórico de los naturales de la isla en la primera mitad del siglo XVI, de acuerdo a los análisis demográficos, así como a resultados de estudios arqueológicos, el examen de las crónicas de indias, y de documentación de archivos y otras fuentes. De esta forma, nos adentra en sucesivos "parte aguas" que tienen su primer pináculo de consideración en las leyes nuevas en 1542 y en los fenómenos asociados a ellas. En ese sentido, son de sumo interés importantes descubrimientos de los últimos ańos donde pesan, los estudios del autor en la zona Holguín, así como otros en las regiones de Camagüey y Jaguaní, hechos por el investigador Tamames Henderson, además de estudios en Bayamo y las estadísticas del conocido historiador Leví Marrero.

El capítulo también es novedoso por el tratamiento que hace de la vida del indio durante los siglos XvII y XVIII, y por las indagaciones en áreas geográficas más allá de las tradicionalmente relacionadas. Valcárcel termina su artículo al abordar el presunto fin de las comunidades indias en 1846-1849, y considerando su aporte a la identidad y su impronta biológica demostrada en los más recientes estudios de genética.

El capítulo "Problema del indio en Cuba" del Dr. Pedro Pablo Godo Torres una vez más, nos sitúa frente a este problema, valora su estado actual y propone alternativas para su solución. Lo más notorio es que lo hace con una prosa reflexiva, discursiva, fresca, recurrente y metafórica, sin llegar a lo coloquial, aspecto que deberíamos tener más presente los arqueólogos al intentar reconocer a nuestras sociedades primigenias.

A partir de la disquisición teórica de si es encuentro, encontronazo, transculturación, deculturación u otras variables categoriales las que pueden explicar la vida y relación del indio cubano con los demás componentes de la nacionalidad cubana, Godo nos lleva de la mano para reconocer la pervivencia del indio en Cuba en diferentes momentos de la etapa colonial. Para reafirmarlo, penetra en como los estudios sociales y antropológicos se hicieron eco del tema, y demuestra con innumerables elementos y argumentos que la huella dejada no solo está constreñida a su aporte alimentario, a elementos de su cultura material, costumbres, leyendas y tradiciones orales, y va mucho más allá de reconocer aquello que conformó la cultura del bohío, la hamaca, el güiro, el catauro y el guamo.

Por ello este autor, se afilia a los estudios de Joel James o Natalia Bolívar, enfocados en demostrar la relación del indio con los cultos sincréticos, y se vale de otros investigadores para demostrar el vinculo de las religiones animistas y totémicas de los indios y de los llegados de África. En tal sentido, cobra fuerza en el trabajo la relación entre las creencias aborígenes y el espiritismo de cordón en el oriente cubano, también la participación del 
indio en la conformación del culto mariano, según los transcendentales estudios de Olga Portuondo antes mencionados.

Lo más trascendental del estudio de Godo es su consideración sobre la dimensión histórica y social del indio, sistematizada para dar respuesta a los elementos que dan cuerpo a su problemática. Su hilo conductor confiable y sugerente es el reconocimiento de un indio insertado en fenómenos de aculturación, deculturación y neoculturación, al seguir la nada descabellada variable fijada por el estudioso cubano Alexis Rives, la de la integración.

Nos conduce Godo a recordar que el aporte está también a favor de una herencia dejada por el indio para el conocimiento de las propiedades curativas de las plantas, del papel protagónico de los de piel cobriza, como dueńos de solares, de conucos, labranzas, como monteros, milicianos que afrontan los peligros a favor de defender la patria chica, constructores de casas, de fortificaciones, de caminos, rancheadores, responsables de sus reducciones, forjadores, junto a blancos, negros y mulatos, de la formación agraria inicial de oriente cubano. Explora caminos no habituales, los del reconocimiento de la complicidad, pasividad, desunión $\mathrm{y}$ alianzas entre indios y españoles, para que nos acordemos de las provincias indias, de los indios que acumularon bienes, de los que a través de matrimonios con españoles forjaron sociedades locales, del arraigo de los de Yateras, bien entrado el siglo XIX y hasta en el $\mathrm{xx}$.

El capítulo "Sobre nuestras identidades boricuas" de los investigadores Reiniel Rodríguez Ramos y Jaime R. Pagán Jiménez se propone reevaluar el discurso tradicional, tendenciosamente engañoso, sobre la identidad indígena en Puerto Rico, a través de los que los autores denominan diálogos: los de tipo institucional, los de sentido cultural y los de competencia arqueológica.

A través de la crítica a escritos influyentes, desmitifican los diálogos institucionales, esos que procrean las creencias del indio manso, bueno, sumiso al español y cualquier extranjero, ese que homogeniza las sociedades de esa isla en un paisaje monocultural, regido por una interpretación de las crónicas que no reconoce sus prejuicios y extrapola situaciones de otros contextos hacia los propios. Es la crítica a los diálogos donde los indios quedan caracterizados por su falta de voluntad, la capacidad de defensa, las limitaciones físicas, tecnológicas y de idiosincrasias. Son los que venden a escolares y toda la nación festividades, logos, y símbolos a tatuar, donde el indio es sano y simple, despojado de su heterogénea naturaleza, junto a lo negro como reminiscencia de lo esclavo y mundano, mientras lo español es enunciado como lo culto.

Además de abordar el tema de los diálogos culturales y su diversidad, estos investigadores enfatizan en el tema de los diálogos arqueológicos, los que a juicios de ellos refrendan la incapacidad de buena parte de los arqueólogos puertorriqueños para enfrentar o participar en los debates en torno a la pervivencia de lo indígena en tiempos coloniales, precisamente porque su actividad está constreñida a lo sucedido antes del encuentro entre las dos culturas, además de las carencias de una proyección institucional que de riendas sueltas a un plan para identificar arqueológicamente al verdadero indígena, de ahí su propuesta arqueológica con agenda emancipadora.

El capítulo IV "La contribución indígena a la biografía del paisaje cultural de la República Dominicana”, de Jana L. Pesoutova y Corinne L. Hofman, es un estudio novedoso, poco usual en el campo arqueológico, encaminado a reconocer el significado cultural de algunos elementos naturales del paisaje, como sitios sagrados, árboles y plantas, vinculados con los procesos históricos de colonización material y conceptual, en el transcurrir de la conquista. Sirve de pauta a su propósito, el análisis de la representación de los pueblos indígenas y el paisaje de La Española, de acuerdo a los registros históricos europeos, así como las asociaciones 
culturales actuales de elementos del paisaje de República Dominicana con la historia indígena. Para completar su labor, las autoras contrastan datos aislados por su investigación con datos sobre el manejo espiritual del paisaje en contextos europeos, africanos y de Venezuela, y consideran sus vínculos socioculturales e históricos como parte de un proceso transcultural. Se impone entonces la interpretación del marco histórico, el análisis de los cambios conceptuales, y de la interacción que actualmente existe entre los grupos humanos y su entorno.

El capítulo "El colonialismo y las arqueologías del Caribe hispano" del arqueólogo Antonio Curet, no solo es un buen intento de sistematizar lo acontecido en materia arqueológica durante los dos siglos precedentes en las tres grandes Antillas (Cuba, Puerto Rico y La Española), sino también el estado actual de dicha disciplina. Lo interesante de su perspectiva es que, unifica como mal principal la prevalencia del normativismo norteamericano, preferentemente el creado por Irving Rouse, en los estudios de esas tres islas. A pesar de esto, no pierde de vista la diversidad planteada por las especificidades en que se ha desarrollado la arqueología de cada país, y procesos ligados a coyunturas sociopolíticas muy diferentes, con aciertos y desaciertos en la consecución de políticas identitarias y de una arqueología en función de ello. De ahí podemos ver un Puerto Rico atado a nefastos intereses coloniales, dañinos para la arqueología, pero que tiene un potencial de recursos y programas, los cuales, mejor proyectados, pudieran dar loables frutos; una Cuba rectorada en las últimas décadas por un régimen comunista que se preocupó por la búsqueda de nuestras raíces y, con ello, por la consolidación del concepto de patria, pero desarrolló instituciones científicas cuyas teorías y metodologías quedaron ataviadas durante mucho tiempo en un marxismo nutrido en exceso del normativismo y sumido en un enclaustramiento ortodoxo y poco dialéctico; por otro lado, Curet nos define a una República
Dominicana donde a pesar de contar con figuras del mundo arqueológico caribeño, como el arqueólogo, Veloz Maggiolo, ligadas a un marxismo dialéctico, de corte estructural y ecologista, esta sigue estancada en los mismos males que padecen sus dos hermanas antillanas, y con muy pocos jóvenes que quieran levantar las banderas del buen quehacer arqueológico.

El trabajo "Colonialismo, Indigenismo, y Arqueología en República Dominicana: silencios confusos y encubrimientos diversos" del Dr. Jorge Ulloa Hung se propone destacar aspectos básicos del devenir de los estudios sobre el patrimonio cultural indígena en República Dominicana, en su relación con la arqueología, y las expresiones del pensamiento colonial. Su aproximación se realiza analizando enfoques y perspectivas teóricas en tres momentos o etapas esenciales. En el primero, se remonta a los siglos XVIII y XIX donde priman coleccionistas, exploradores y estudiosos enfrascados en destacar un indio bueno y noble, o desaparecido, que en los momentos del auge de la criollidad sirve de pauta para la reafirmación de la identidad, pero no se reconoce como insertado en la sociedad colonial, prevalece el reconocimiento del indio a través de lo descrito en las crónicas, y el quehacer arqueológico incipiente está ligado al evolucionismo de finales del siglo XIX.

En el segundo momento, la realización de estudios arqueológicos y la interpretación de la realidad indígena, se encuentra sujeta a los cánones del particularismo histórico y especialmente de la arqueología normativista, mientras en un tercer momento, en los ańos setenta del siglo xx, las metodologías estuvieron ligadas a un marxismo arropado por la ecología y el materialismo cultural.

Termina la segunda sección de este volumen con el trabajo 'El indígena y el uso de las crónicas de Indias en la historiografía nacional de Cuba" del investigador Ulises M. González Herrera. En este, se realiza una valoración del tratamiento recibido 
por las Crónicas de Indias en el quehacer científico cubano a favor de lograr la reconstrucción etnohistórica del indio, y para lograrlo, realiza un balance de las principales crónicas usadas por historiadores y arqueólogos, desde los llamados primeros historiadores hasta los esfuerzos realizados en el siglo xx y lo que va del xxi. En tal sentido, su juicio es crítico, y especialmente valora las pocas obras que después del triunfo de la revolución cubana se sustentaron en el estudio a fondo de las Crónicas de Indias, y cómo esos juicios han estado muchas veces ausente en las reconstrucción de la vida del indígena, o mayormente desligadas de los estudios arqueológicos. El autor realiza propuestas para empezar a superar tales problemas.

Por último, como anunciamos al inicio, la última sección del volumen es un justo homenaje a quienes constituyen algunos de los principales maestros en la formación arqueológica de generaciones de arqueólogos cubanos y dominicanos.

Marcio Valoz Maggiolo en su ensayo "Literatura y Arqueología", cabalga de nuevo con la esencia de sus novelas La mosca soldado y Florbella, con la intención de mostrarnos que toda obra arqueológica y literaria, forjada o no en una precedente, tiene muchas lecturas, lo mismo para el receptor que para el autor de acuerdo a las cambiantes circunstancias vitales. En ese sentido, esta nueva interpretación de su obra tiene una génesis central, y nada mutable, en la existencia de un protagonista fundamental y verdadero en toda la historia contada: el Dr. Fernando Luna Calderón, fecundo antropólogo físico de las excavaciones de el Soco y otras partes de las Antillas.

Por su parte, la profesora María Nelsa Tricado nos legó hace ya algunos años "El indígena y la formación de la nacionalidad cubana", como una especie de campana precursora que llamaba al rescate del indio como importante componente de la nacionalidad cubana, valorando su contribución en aristas poco tratadas como los cultos sincréticos, y en las formas en que aportó sus conocimientos a la supervivencia de españoles y negros. Distinciones precursoras que hoy tienen mayor sonido de alerta y maduración en libros como este.

\section{Datos de filiación}

Juan Manuel Reyes Cardero. Nació el 6 de febrero de 1964. Licenciado en Historia (1987) y Máster en Estudios Cubanos y del Caribe (2000) por la Universidad de Oriente, Santiago de Cuba. Es investigador de la Oficina del Historiador de la ciudad de Santiago de Cuba, ha publicado más de 40 artículos en libros, revistas y publicaciones nacionales y extranjeras. Tiene varios trabajos en la revista especializada El Caribe Arqueológico y uno de sus libros es Santiago colonial, arqueología e historia.

Correo electrónico: jmanuel@ohc.occ.co.cu 